\title{
A placebo-controlled study of three osteocalcin assays for assessment of prednisolone-induced suppression of bone turnover
}

\author{
C Heuck and O D Wolthers \\ Department of Paediatrics, Aarhus University Hospital, Aarhus, Denmark \\ (Requests for offprints should be addressed to O D Wolthers, Department of Paediatrics, Randers Hospital, DK-8900 Randers, Denmark)
}

\begin{abstract}
Serum osteocalcin is a sensitive marker of suppressive effects of exogenous glucocorticoids on bone turnover. It has been suggested, however, that the degree of suppression detected by different assays may vary. Whether discrepancies between various assays influence conclusions from group studies of exogenous glucocorticoids has not been evaluated. The aim of the present study was to compare the CAP fluoroimmunoassay (FEIA), OSTK-PR and ELSA-OSTEO assays for assessment of prednisoloneinduced effects on serum osteocalcin. Twelve men and eight premenopausal women aged 19-45 (mean 31) years were studied. All subjects were healthy. The design was a randomised double-blind, placebo-controlled parallelgroup study with 2 days run-in, 3 days treatment and 4
\end{abstract}

days run-out. During run-in and run-out no medication was given. During the treatment period the subjects took either $20 \mathrm{mg}$ prednisolone twice daily or placebo. Blood was collected on the last day of each period. Intra- and intergroup comparisons showed prednisolone treatment to be associated with a statistically significant suppression of osteocalcin which was detected by all assays (ANOVA; $P<0 \cdot 0001)$. In the individual subjects the response to prednisolone was the same for each assay. The CAP FEIA, OSTK-PR and ELSA-OSTEO assays seem equally sensitive for evaluation of osteocalcin in group studies of oral glucocorticoids.

Journal of Endocrinology (1998) 159, 127-131

\section{Introduction}

Osteocalcin is the most abundant noncollagenous protein of bone. It is synthesised only by the osteoblasts, and changes in osteoblast activity correlate with variations in serum concentrations of osteocalcin (Nielsen et al. 1988b). Serum osteocalcin has been established as a sensitive marker of suppressive effects of exogenous glucocorticoids on bone turnover (Nielsen et al. 1988a,b, Meeran et al. 1995). Systemic glucocorticoids cause a dose-dependent reduction in osteocalcin levels (Hodsman et al. 1991, Wolthers et al. 1993). It has been suggested, however, that the degree of glucocorticoid suppression detected by various assays may vary, whereby interpretation of osteocalcin in individual patients treated with exogenous glucocorticoids becomes difficult (Masters et al. 1994). Whether discrepant test results may influence conclusions from group studies of exogenous glucocorticoids has not been evaluated. Therefore, the aim of the present study was to assess whether prednisolone treatment is associated with any adverse effects on serum osteocalcin using three osteocalcin assays.

\section{Subjects and Methods}

Twelve men and eight women aged 19-45 (mean 31) years, doctors and nurses, laboratory workers and students at our department, were asked and agreed to participate in the study. The subjects were carefully screened by medical examination and proved healthy without any history of metabolic or renal disease. None of them had ever received treatment with exogenous glucocorticoids and no other drugs were taken 2 months before or during the study period. All subjects were non-smokers. None of the females was pregnant or had menstruation during the study. All subjects entered the study on the same day, and they continued their usual activities throughout the study. The study was approved by the local ethics committee, and each subject gave informed consent before the study.

The design was a randomised double-blind, placebocontrolled parallel-group study with 2 days run-in, 3 days treatment and 4 days run-out. During run-in and run-out no medication was given. During the treatment period the subjects took either prednisolone (40 mg per day) or placebo. Allocation to treatment was performed by means of a computerised randomisation scheme prepared in balanced blocks. Prednisolone and placebo were divided into two daily doses and taken in the morning at $0700 \mathrm{~h}$ and in the evening at $1900 \mathrm{~h}$. The tablets, identical in size and appearence, were delivered in identical glasses labelled with case number and prescription. Tablets were counted before and after the treatment period. 
Table 1 Characteristics of the osteocalcin assays

\begin{tabular}{|c|c|c|c|c|}
\hline \multirow[b]{3}{*}{ Assay } & \multirow[b]{2}{*}{ Type } & \multirow[b]{2}{*}{ Antibody } & \multicolumn{2}{|c|}{ Variation (\%) } \\
\hline & & & Intra-assay & Interassay \\
\hline & & & & \\
\hline CAP & FEIA & Antihuman $\mathrm{OC}, \mathrm{mAb}$ & $6 \cdot 2$ & $4 \cdot 1$ \\
\hline ELSA-OSTEO & Sandwich RIA & Antihuman $\mathrm{OC}, \mathrm{mAb}$ & $5 \cdot 4$ & $5 \cdot 0$ \\
\hline OSTK-PR & Competitive RIA & Rabbit anti-bovine OC & $5 \cdot 5$ & $5 \cdot 2$ \\
\hline
\end{tabular}

OC, osteocalcin; mAb, monoclonal antibody.

Glass tubes without clot accelerators were used for the collection of blood which took place during the afternoon between 1300 and $1700 \mathrm{~h}$ on the last day of the run-in, treatment and run-out periods. The blood samples were taken at roughly the same time (that is, within $30 \mathrm{~min}$ ) and were centrifuged at 4000 r.p.m. for $10 \mathrm{~min}$ within $1 \mathrm{~h}$ of collection. After centrifugation serum samples were stored in plastic tubes at $-80{ }^{\circ} \mathrm{C}$, and they were thawed only once, i.e. immediately before they were batch assayed at completion of the study, each sample being run in all three assays at the same time. Haemolysed samples were not used for analysis. The osteocalcin assays used were Pharmacia Osteocalcin CAP fluoroimmunoassay (FEIA) (Kabi Pharmacia Diagnostics AB 1994) and CIS Human Osteocalcin IRMA (ELSA-OSTEO) (Cis Bio International 1994) and RIA (OSTK-PR) (CIS Bio International 1995). Details of the assays are given in Table 1. In the CAP FEIA osteocalcin standards were calibrated against a reference standard, which was prepared according to a modified method (Taylor et al. 1988) and quantified by amino acid analysis. In the ELSA-OSTEO and OSTK-PR assays animal proteins (ELSA-OSTEO) and bovine osteocalcin and human proteins (OSTK-PR) were used in lyophilised standards. Normal ranges of serum osteocalcin depend on sex, age and the assay used (Gundberg et al. 1985, Tarallo et al. 1990). Preliminary assessments using the CAP FEIA, OSTK-PR and ELSAOSTEO assays have found normal ranges of 1-25, 1-18 and $5-35 \mu \mathrm{g} / 1$ respectively, in 20 - to 50 -year-old men, and of $1-15,1-13$ and $8-36 \mu \mathrm{g} / 1$ respectively, in $20-$ to 50-year-old, premenopausal women (Kabi Pharmacia Diagnostics AB 1994, CIS Bio International 1994, 1995).

\section{Statistics}

Data are described as means \pm standard error of the means. To evaluate differences between run-in, treatment and run-out periods in the placebo group, one-way analysis of variance on ranks was performed. Differences within the prednisolone group were compared by one-way analysis of variance followed by Student-Newman-Keuls multiple range test. Intergroup comparisons were performed with Students's $t$-test for unpaired samples if data fulfilled conditions for parametric analysis, otherwise the Mann-
Whitney rank sum test was used. To assess whether the response of osteocalcin to prednisolone was the same for each assay the percentage change of prednisolone to run-in values was evaluated by the method described by Bland \& Altman (1986). The 5\% level of significance was used. All statistics were performed using the SOLO Statistical Software package (BMDP Statistical Software, Los Angeles, CA, USA).

\section{Results}

Six males and three females (age range (mean): 27-44 (33) years) were allocated to treatment with prednisolone, and six males and five females (19-45 (29) years) were allocated to placebo treatment. Height, weight and body surface area (range (mean)) were 161-184 (174) cm, 60-81 (69) kg, $1 \cdot 7-2 \cdot 0(1 \cdot 8) \mathrm{m}^{2}$ in the prednisolone group, and 165-200 (177) cm, 57-114 (72) kg, 1.6-2.5 (1.9) $\mathrm{m}^{2}$ in the placebo group. There were no significant demographic differences between the groups. Compliance with dosage regimen was $100 \%$ in both groups during all periods. The treatment blood sample from one male in the placebo group was lost, and a male in the prednisolone group forgot his run-out appointment and, therefore, did not have blood collected during that period.

Individual values of serum concentrations of osteocalcin during run-in, treatment and run-out are shown in Fig. 1. All data showed a Gaussian distribution. Group means and the results of intra- and intergroup comparisons are given in Table 2. The intra-group comparisons show that prednisolone treatment was associated with a statistically significant suppression of osteocalcin which was detected by all assays. Furthermore, osteocalcin values returned to pretreatment levels during run-out. In the placebo group osteocalcin levels were constant throughout all periods. The results of the intergroup analyses based on each assay were consistent with the intra-group comparisons. Figure 2 shows the plots of the pairwise comparisons of the CAP FEIA, OSTK-PR and ELSA-OSTEO assays respectively, in the prednisolone-treated group based on the percentage of prednisolone to run-in values in all subjects. In the individual subjects the response to prednisolone was similar for each assay. 
CAP FEIA
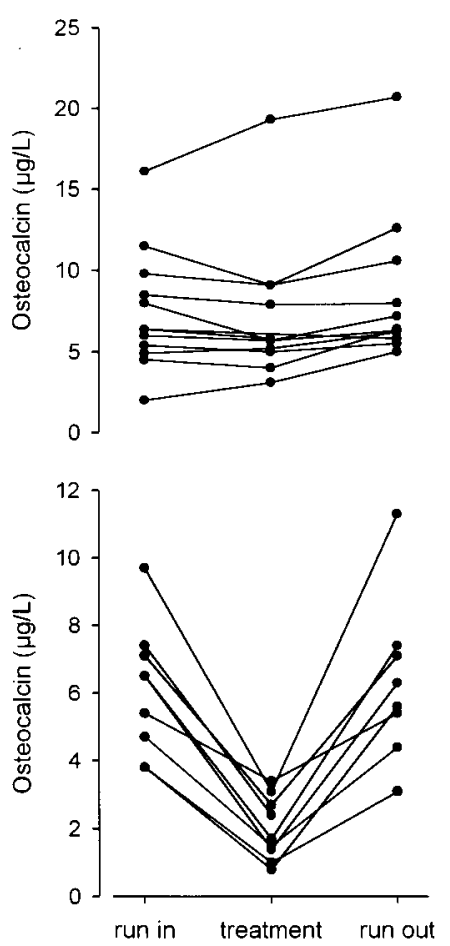

OSTK-PR
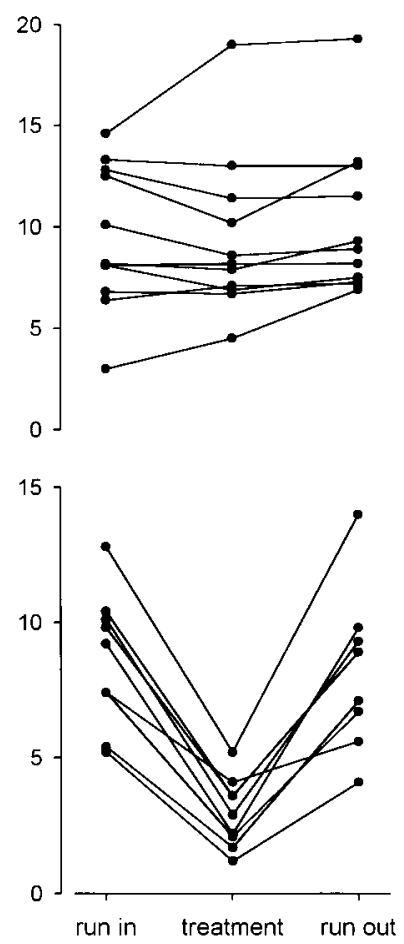

ELSA-OSTEO
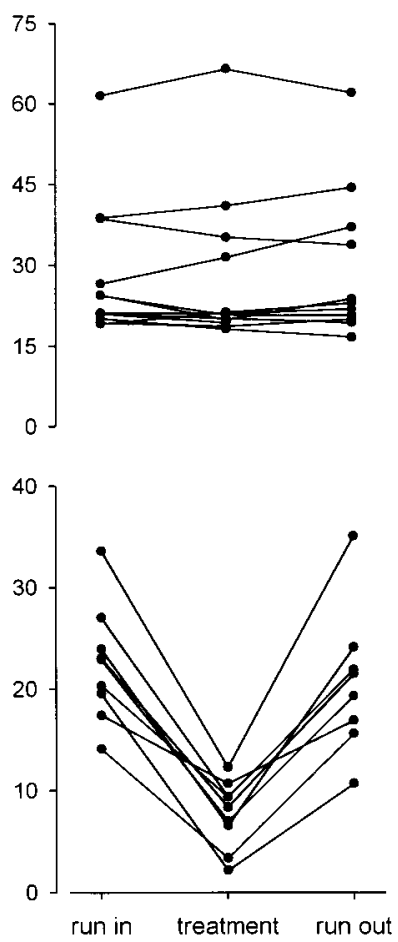

Figure 1 Run-in, treatment and run-out serum concentrations of osteocalcin measured with the CAP FEIA, OSTK-PR and ELSA-OSTEO assays in 11 subjects treated with placebo (upper panel) and 9 subjects treated with prednisolone $20 \mathrm{mg}$ twice daily (lower panel).

\section{Discussion}

Most of the commercially available osteocalcin assays are based on radioimmunoassay techniques some of which use polyclonal, others monoclonal antibodies (Delmas et al. 1990, Diaz Diego et al. 1994, Garnero et al. 1994, Masters et al. 1994, Blumsohn et al. 1995, Cecchettin et al. 1995). The OSTK-PR assay applies polyclonal antibodies raised against bovine osteocalcin. It is the most widely used reference. We, therefore, compared this and an assay which applies monoclonal antibodies raised against human osteocalcin, the ELSA-OSTEO assay, with the recently introduced fluorescence immunoassay based on immuno CAP technology using monoclonal antibodies raised against human osteocalcin.

The absolute osteocalcin values determined by different assays may depend on assay type (RIA, FEIA), standardisation (human, bovine), antibody type (monoclonal, polyclonal), calcium dependency (Tracy et al. 1990), sensitivity, recovery, precision and specificity of the assay (human, bovine, intact osteocalcin molecule, C-terminal end of the molecule) (Delmas et al. 1990). Different assays may measure different fragments of the osteocalcin polypeptide (Deftos et al. 1992). In the ELSA-OSTEO assay the antibody tracer is directed against part of the osteocalcin molecule whereby intact osteocalcin as well as degradation products may be measured (Diaz Diego et al. 1994). A combination of one or more of the abovementioned factors may explain why higher values were detected by the ELSA-OSTEO assays compared with the CAP FEIA which detects intact osteocalcin only (Kabi Pharmacia Diagnostics AB 1994). The epitopes bound by the antiserum used in the OSTK-PR assay have not been described and further studies addressing specificity and reactivity of osteocalcin assays are needed before these interassay variations can be fully understood. The results of the present study, however, confirm the reliability of the CAP FEIA for determination of serum osteocalcin in glucocorticoid-treated subjects. During prednisolone treatment reduced osteocalcin levels were detected by all assays in each patient and overall. So, although the degree of suppression may vary between assays and may confound osteocalcin data in patients with various bone disorders (Masters et al. 1994), the CAP FEIA, OSTK-PR and ELSA-OSTEO assays seem equally reliable for evaluation of osteocalcin in group studies of exogenous glucocorticoids.

Besides dose, the degree of suppression of serum concentrations of osteocalcin observed in individuals during glucocorticoid treatment may depend on several factors 
Table 2 Serum concentrations ( $\mathrm{g} / \mathrm{l}$ ) of osteocalcin (group means \pm S.E.M.) based on the CAP FEIA, OSTK-PR and ELSA-OSTEO assays and intra- and intergroup comparisons ( $P$ values) in 11 subjects treated with placebo and 9 subjects treated with prednisolone (20 mg twice daily).

\begin{tabular}{|c|c|c|c|}
\hline & CAP FEIA & OSTK-PR & ELSA-OSTEO \\
\hline \multicolumn{4}{|l|}{ Placebo group } \\
\hline Run-in $(n=11)$ & $7 \cdot 55 \pm 1 \cdot 17$ & $9 \cdot 45 \pm 1 \cdot 07$ & $28 \cdot 64 \pm 3 \cdot 92$ \\
\hline Treatment $(n=10)$ & $7 \cdot 41 \pm 1 \cdot 49$ & $9 \cdot 53 \pm 1 \cdot 31$ & $29 \cdot 42 \pm 4 \cdot 82$ \\
\hline Run-out $(n=11)$ & $8 \cdot 57 \pm 1 \cdot 40$ & $10 \cdot 21 \pm 1 \cdot 14$ & $29 \cdot 34 \pm 4 \cdot 18$ \\
\hline \multicolumn{4}{|l|}{ Statistical comparisons } \\
\hline ANOVA & $0 \cdot 54^{*}$ & $0 \cdot 76^{*}$ & $0 \cdot 95^{*}$ \\
\hline \multicolumn{4}{|l|}{ Prednisolone group } \\
\hline Run-in $(n=9)$ & $6 \cdot 10 \pm 0 \cdot 64$ & $8.63 \pm 0.83$ & $22 \cdot 41 \pm 1 \cdot 89$ \\
\hline Treatment $(n=9)$ & $2 \cdot 00 \pm 0 \cdot 31$ & $2 \cdot 96 \pm 0 \cdot 43$ & $7 \cdot 71 \pm 1 \cdot 10$ \\
\hline Run-out $(n=8)$ & $6 \cdot 33 \pm 0 \cdot 87$ & $8 \cdot 19 \pm 1 \cdot 08$ & $20 \cdot 64 \pm 2 \cdot 55$ \\
\hline \multicolumn{4}{|l|}{ Statistical comparisons } \\
\hline ANOVA & $<0 \cdot 0001$ & $<0 \cdot 0001$ & $<0 \cdot 0001$ \\
\hline Run-in vs treatment & $<0.05$ & $<0.05$ & $<0.05$ \\
\hline Treatment vs run-out & $<0 \cdot 05$ & $<0 \cdot 05$ & $<0 \cdot 05$ \\
\hline Run-in vs run-out & NS & NS & NS \\
\hline \multicolumn{4}{|c|}{ Placebo vs prednisolone group } \\
\hline \multicolumn{4}{|c|}{ Statistical comparisons } \\
\hline Run-in & $0 \cdot 32$ & 0.57 & $0 \cdot 32^{* *}$ \\
\hline Treatment & $<0.0001^{* *}$ & $<0.0005$ & $<0.001^{* *}$ \\
\hline Run-out & $0 \cdot 23$ & $0 \cdot 23$ & $0 \cdot 12$ \\
\hline
\end{tabular}

*ANOVA on ranks; **Mann-Whitney rank sum test.

NS, not significant.

such as individual variations in metabolism and sensitivity to exogenous glucocorticoids, concurrent administration of topical glucocorticoids, potency of the drug used and administration regimen (Reid 1989, Wolthers et al. 1993, Knutsson et al. 1995, Morice et al. 1996). Long term treatment is associated with a significant risk of osteopenia (Reid 1989). To reduce the risk in many conditions short term treatment regimens are used (Toogood \& Hodsman 1991, Lems et al. 1993, Wolthers et al. 1996). Since an exponential decline in bone mass has been found with the highest bone loss within 6 months of treatment and a much slower rate of loss after 12 months of treatment (LoCascio et al. 1990), short term evaluations of bone turnover focusing specifically on the relation between duration of treatment and duration of possible adverse effects on bone turnover are needed. In the present study we wanted to assess an administration regimen which is used in a variety of conditions (Toogood \& Hodsman
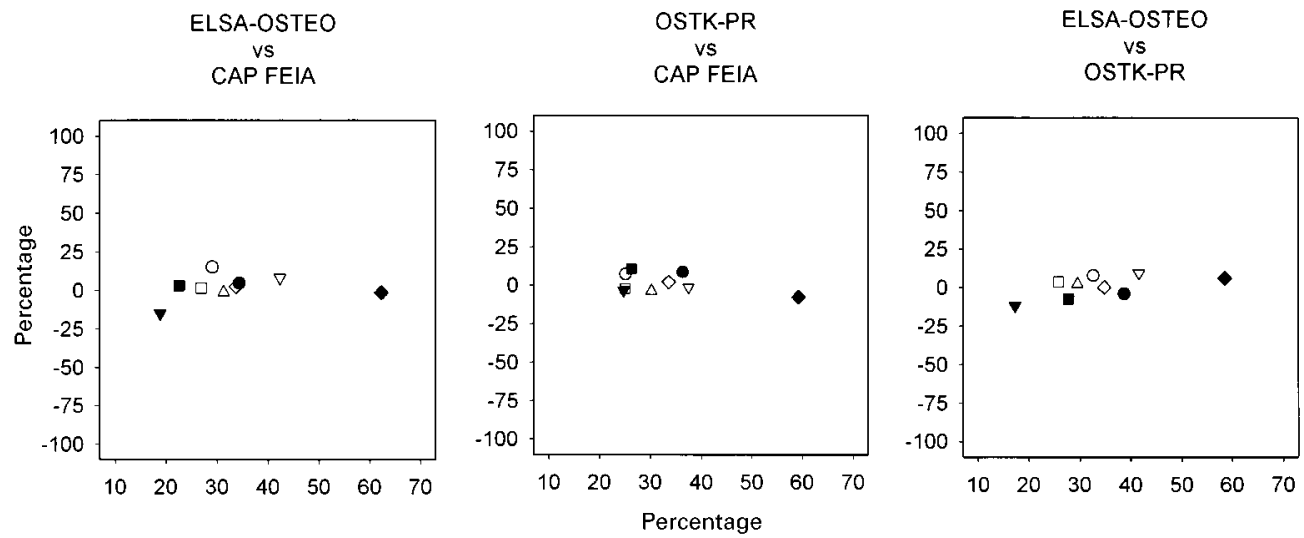

Figure 2 Means ( $x$ axis) and differences ( $y$ axis), expressed as percentages of run-in levels, of pairwise comparisons of osteocalcin values assessed by the CAP FEIA, OSTK-PR and ELSA-OSTEO assays during prednisolone treatment. The different marks identify the 9 individual subjects in each panel. 
1991). Our findings are in accord with reports that prednisone and prednisolone $20 \mathrm{mg}$ twice daily for 5 and 10 days respectively, are associated with suppressed osteocalcin levels (Nielsen et al. 1988b, Hodsman et al. 1991, Lane et al. 1996). The duration of the suppression of osteocalcin after a single administration of $10 \mathrm{mg}$ prednisone seems to be approximately $16 \mathrm{~h}$ (Nielsen et al. 1988a). The duration of suppression after withdrawal of several days of treatment, however, has not previously been assessed. This is an important factor to consider since a cumulatative suppresssive effect may play a key role in the early and rapid bone loss which occurs during treatment with exogenous corticosteroids (Reid 1989, LoCascio et al. 1990, Worth et al. 1994). The present findings have provided evidence that 4 days after withdrawal of a 3-day course of prednisolone $(20 \mathrm{mg}$ twice daily) bone turnover is unaffected. So, the risk of long term effects of short term treatment can be ignored. The risk of a suppressive effect on bone turnover from intermittent short term treatment with exogenous glucocorticoids, however, may need further evaluation in the intermediate and long term perspectives.

\section{References}

Bland JM \& Altman DG 1986 Statistical methods for assessing agreement between two methods of clinical measurement. Lancet 1986 i 307-310.

Blumsohn A, Hannon RA \& Eastell R 1995 Apparent instability of osteocalcin in serum as measured with different commercially available immunoassays. Clinical Chemistry 41 318-319.

Cecchettin M, Bellometti S, Torri G \& Galzigna L 1995 Comparison of commercial osteocalcin assay kits in evaluating osteoporosis. Current Therapeutic Research 56 163-168.

Cis Bio International 1994. ELSA-OSTEO. Gif-Sur-Yvette Cedex, France.

Cis Bio International 1995. OSTK-PR. Gif-Sur-Yvette Cedex, France.

Deftos LJ, Wolfert RL, Hill CS \& Burton DW 1992 Two-site assays of bone gla protein (osteocalcin) demonstrate immunochemical heterogeneity of the intact molecule. Clinical Chemistry $\mathbf{3 8}$ 2318-2321.

Delmas PD, Christiansen C, Mann KG \& Price PA 1990 Bone Gla protein (osteocalcin) assay standardization report. Journal of Bone and Mineral Research 5 5-11.

Diaz Diego EM, Guerrero R \& de la Piedra C 1994 Six osteocalcin assays compared. Clinical Chemistry 40 2071-2077.

Garnero P, Grimaux M, Seguin P \& Delmas PD 1994 Characterization of immunoreactive forms of human osteocalcin generated in vivo and in vitro. Journal of Bone and Mineral Research 9 $255-264$.

Gundberg CM, Markowitz ME, Mizruchi M \& Rosen JF 1985 Osteocalcin in human serum: a circadian rhythm. Journal of Clinical Endocrinology and Metabolism 60 736-739.

Hodsman AB, Toogood JH, Jennings B, Fraher LJ \& Baskerville JC 1991 Differential effects of inhaled budesonide and oral prednisolone on serum osteocalcin. Journal of Clinical Endocrinology and Metabolism 72 530-540.

Kabi Pharmacia Diagnostics AB 1994 Pharmacia CAP system osteocalcin FEIA. Uppsala, Sweden: Kabi Pharmacia Diagnostics $\mathrm{AB}$.
Knutsson U, Stierna P, Marcus C, Carlstedt Duke J, Carlstrom K \& Bronnegard M 1995 Effects of intranasal glucocorticoids on endogenous glucocorticoid peripheral and central function. Journal of Endocrinology 144 301-310.

Lane SJ, Vaja S, Swaminathan R \& Lee TH 1996 Effects of prednisolone on bone turnover in patients with corticosteroid resistant asthma. Clinical and Experimental Allergy 26 1197-1201.

Lems WF, Jacobs JW, van den Brink HR, van Rijn HJ \& Bijlsma JW 1993 Transient decrease in osteocalcin and markers of type 1 collagen turnover during high-dose corticosteroid pulse therapy in rheumatoid arthritis. British Journal of Rheumatology 32 787-789.

LoCascio V, Bonucci E, Imbimbo B, Ballanti P, Adami S, Milani S, Tartarotti D \& DellaRocca C 1990 Bone loss in response to long-term glucocorticoid therapy. Bone and Mineral 8 39-51.

Masters PW, Jones RG, Purves DA, Cooper EH \& Cooney JM 1994 Commercial assays for serum osteocalcin give clinically discordant results. Clinical Chemistry 40 358-363.

Meeran K, Hattersley A, Burrin J, Shiner R \& Ibbertson K 1995 Oral and inhaled corticosteroids reduce bone formation as shown by plasma osteocalcin levels. American Journal of Respiratory and Critical Care Medicine 151 333-336.

Morice AH, Morris D \& Lawson MP 1996 A comparison of nebulized budesonide with oral prednisolone in the treatment of exacerbations of obstructive pulmonary disease. Clinical Pharmacology and Therapeutics 60 675-678.

Nielsen HK, Charles P \& Mosekilde L 1988a The effect of single oral doses of prednisone on the circadian rhythm of serum osteocalcin in normal subjects. Journal of Clinical Endocrinology and Metabolism 67 1025-1030.

Nielsen HK, Thomsen K, Eriksen EF, Charles P, Storm T \& Mosekilde L $1988 b$ The effects of high-dose glucocorticoid administration on serum bone gamma carboxyglutamic acidcontaining protein, serum alkaline phosphatase and vitamin D metabolites in normal subjects. Bone and Mineral 4 105-113.

Reid IR 1989 Pathogenesis and treatment of steroid osteoporosis. Clinical Endocrinology 30 83-103.

Tarallo P, Henny J, Fournier B \& Siest G 1990 Plasma osteocalcin: biological variations and reference limits. Scandinavian Journal of Clinical and Laboratory Investigation 50 649-655.

Taylor AK, Linkhart SG, Mohan S \& Baylink DJ 1988 Development of a new radioimmunoassay for human osteocalcin: evidence of a midmolecule epitope. Metabolism 37 872-877.

Toogood JH \& Hodsman AB 1991 Effects of inhaled and oral corticosteroids on bone. Annals of Allergy 67 87-90.

Tracy RP, Andrianorivo A, Riggs BL \& Mann KG 1990 Comparison of monoclonal and polyclonal antibody-based immunoassays for osteocalcin: a study of sources of variation in assay results. Journal of Bone and Mineral Research 5 451-461.

Wolthers OD, Riis BJ \& Pedersen S 1993 Bone turnover in asthmatic children treated with oral prednisolone or inhaled budesonide. Pediatric Pulmonology 16 341-346.

Wolthers OD, Heuck C, Ternowitz T, Heickendorf L, Nielsen HK \& Frystyk J 1996 The insulin-like growth factor axis and bone and collagen turnover in children with atopic dermatitis treated with topical glucocorticosteroids. Dermatology 192 337-342.

Worth H, Stammen D \& Keck E 1994 Therapy of steroid-induced bone loss in adult asthmatics with calcium, vitamin $\mathrm{D}$, and a diphosphonate. American Journal of Respiratory and Critical Care Medicine 150 394-397.

Received 1 December 1997

Revised manuscript received 30 April 1998 Accepted 29 May 1998 